\title{
Why are patients scared away from private stem cell treatment clinics?
}

\begin{abstract}
James L Sherley*
Asymmetrex LLC, Boston, USA

When it comes to stem cell therapies, are FDA-approved clinical trials really any better for patients than treatments in private stem cell clinics? Actually, not really. In recent months, the National Institutes of Health (NIH), [1] the International Society for Stem Cell Research (ISSCR), [2] and independent science bloggers (e.g., The Niche) [3] seem to be in collusion to scare patients away from private stem cell treatment clinics. Online they offer long lists of reasons why such medical clinics are likely to be exploitive and even dangerous.
\end{abstract}

\section{Not so different treatments}

These lists are remarkably one-sidedly negative against stem cell clinics. They have nothing positive to say about stem cell clinics. Surely, among the estimated more than 400 private medical clinics in the U.S. alone [4] that offer "unproven" stem cell treatments, one or two might be providing benefits to patients, even if not caused by stem cells per se. Very likely, the developers of the scare lists have not actually met any of the doctors who are attempting to evaluate a new therapeutic modality for their patients with the best medical judgment and best intentions for doing good. Instead, the scare lists judge them all to be greedy, exploitive, and unethical.

The NIH, ISSCR, and The Niche hold up idealized FDA-approved clinical trials as the gold standard against which treatments in private stem cell clinics are compared to disparage. But in reality, stem cell clinical trials are a disingenuous basis for criticism. Treatments that patients receive in clinical trials are also unproven. The trials are "approved," but the treatments evaluated in the trials are not. They are experimental. Moreover, many of the complaints launched against treatments in private clinics also apply to treatments in clinical trials. For example, referring to the current practice of using stem cells isolated from one tissue to treat disease or injury in a different tissue, the ISSCR's scare list states, "Thus, it is unlikely that a single cell type can be used to treat a multitude of unrelated diseases involving different tissues or organs" and "How and where the cells are put back into your body matters, and some clinics inject cells into places where they are not normally present and do not belong [2]." Yet, more than half of approved clinical trials are designed to evaluate just this hypothesis that stem cells may confer healing properties to heterologous tissues [5].

The cause for the disdain that these leading organizations, which declare dedication to advancing stem cell medicine, express against stem cell treatment physicians who share the same dedication is unclear. In their missions to serve patients, the NIH's and ISSCR's efforts would seem to be better spent informing patients how to obtain the best care in either setting, recognizing their individual strengths and weaknesses. In both settings, the safety and quality of care received by patients rest in the hands of the treating physicians and their staff. Clinical trials do provide the added societal value of monitored documentation of treatments, which may lead to more rapid extension of findings to more patients. However, the potential for individual medical investigations to lead to important scientific insights and medical progress should not be overlooked [6], as is done by the scare lists.

\section{An unstated mutual shortcoming}

Oddly, there is one shortcoming of both types of experimental stem cell treatments that does not appear in the scare lists. They do not disclose that the dose of the most important principle in the treatments, the stem cells, is unknown. The lack of dosing data means that stem cell clinics use stem cell preparations from suppliers without knowing if they contain any stem cells. Physicians who prepare stem cells for injection in their own clinics cannot relate treatment outcomes for different patients, or even multiple treatments in the same patient, to the number of stem cells injected. Such a knowledge gap makes it impossible to achieve reliable, standardized treatment procedures for stem cell medicine. Perhaps the reason that this crucial gap is not mentioned on the scare lists is that all gold standard FDA-approved stem cell clinical trials have the very same gap in knowledge. As a result, the treatment outcomes of stem cell clinical trials are also not interpretable. Because the number of stem cells in treatment samples is unknown, there is no way to accurately attribute differences in outcomes to effects of stem cells.

The present dosing gap in stem cell medicine is a critical treatment issue that every patient should ask their treating physician to address, whether they are considering a private clinic or enrolling in a clinical trial. Every patient should inquire how physicians are ensuring that their patients receive a known number of active stem cells. This information is no less important than knowing the dose and the quality of the medicine they would receive for a conventional medical treatment or in a drug trial.

\section{A new standard for stem cell transplantation medicine}

After more than five decades of disappointed efforts, stem cell medicine had become resigned to the belief that difficulty counting tissue stem cells was an immovable barrier to progress. Stem cells are a tiny fraction of total tissue cells, and biomarkers for their specific identification have proven elusive. However, now, new technologies are emerging that make it possible to conveniently and accurately determine the number and quality of stem cells in treatment preparations from any human tissue. With the knowledge of these new technologies, the FDA, patients, and patient advocate groups should now demand a new standard for experimental stem cell treatments,

Correspondence to: James L Sherley, Director, Asymmetrex LLC, P.O. Box 301179, Boston, MA 02130, USA, Tel: 617-990-6819; E-mail: jsherley@asymmetrex.com

Received: April 07, 2017; Accepted: May 05, 2017; Published: May 08, 2017 
whether private or FDA-regulated. That new standard is knowledge of the dose of treating stem cells.

The rate of progress with new stem cell medicines will depend on the outcome of ongoing evaluations, including those in stem cell clinical trials as well as those in private stem cell clinics. To insure the safest and most effective investigations in either setting, certification of the dose and quality of transplanted stem cells must become an essential treatment standard. When patients begin to demand this standard of quality assurance, scare lists can be retired to the waste bin of past scientific and medical transgressions that harmed patients by under informing them.

\section{Acknowledgement:}

James L. Sherley, M.D., Ph.D. founded Asymmetrex in 2013. Under his leadership as Director, Asymmetrex recently launched a contract service for counting human tissue stem cells for applications in stem cell medicine and drug development.

\section{References}

1. https://stemcells.nih.gov/info/health.htm

2. http://www.closerlookatstemcells.org/stem-cells-and-medicine/nine-things-to-knowabout-stem-cell-treatments

3. http://www.ipscell.com/patients-guide-to-stem-cell-treatments/

4. Turner L, Knoepfler P (2016) Selling stem cells in the USA: assessing the direct-toconsumer industry. Cell Stem Cell.

5. Li MD, Atkins H, Bubela T (2014) The global landscape of stem cell clinical trials Regen Med 9: 27-39.

6. Sherley JL (2016) Advancing stem cell medicine by supplying private stem cell clinics http://www.clinicaltrialsarena.com/news/supply-chain/advancing-stem-cellmedicine-

Copyright: $\odot 2017$ Sherley JL. This is an open-access article distributed under the terms of the Creative Commons Attribution License, which permits unrestricted use, distribution, and reproduction in any medium, provided the original author and source are credited. 